\title{
KAJIAN PENGGUNAAN OPC SERVER UNTUK PEMBUATAN PENAMPIL DAYA REAKTOR
}

\section{STUDY OF USING OPC SERVER FOR MAKING REACTOR POWER VIEWERS}

\author{
Sukarno Sigit ${ }^{1}$, Heri Suherkiman ${ }^{2}$, Susanto ${ }^{3}$ \\ 1,2,3PRSG-BATAN, Kawasan Puspiptek Gd.30,Serpong,15310 \\ E-mail : Sukarno100483@gmail.com
}

Diterima: 26 September 2019, diperbaiki : 1 Oktober 2019, disetujui : 13 Oktober 2019

\begin{abstract}
ABSTRAK
KAJIAN PENGGUNAAN OPC SERVER UNTUK PEMBUATAN PENAMPIL DAYA REAKTOR . Mode operasi reaktor RSG-GAS meliputi daya rendah (KW) hingga daya tinggi (MW). Saat ini penampil daya hanya menampilkan daya dalam orde MW. Untuk itu perlu dibuat penampil daya yang mampu menampilkan daya dalam range yang lebih lebar untuk melengkapi penampil daya yang ada. Perangkat penampil digital daya reaktor dibangun dengan perangkat OPC server, labview dan memanfaatkan kanal daya JKT04 yang digunakan sebagai pedoman penentuan besar daya reaktor. Dari hasil pengujian, program penampil digital daya reaktor berhasil menampilkan daya reaktor dari orde KW sampai dengan MW dan perhitungan faktor konversi arus JKT04 (ampere) ke skala daya (watt) dapat dilakukan secara akurat dan otomatis. Semua hasil perhitungan program dapat disimpan ke dalam file dalam format excel sebagai basis data.Perangkat ini dapat diterapkan di RSG-GAS dengan harapan dapat digunakan sebagai penampil daya untuk operasi daya rendah hingga daya tinggi dan sebagai sarana untuk menunjang penelitian tentang daya reaktor.
\end{abstract}

Kata Kunci :Penampil daya, Faktor Konversi, Kanal daya, OPC server

\begin{abstract}
STUDY OF USING OPC SERVER FOR MAKING REACTOR POWER VIEWERS. The operation modes of the RSG-GAS reactor include low power (kW) to high power (MW). Currently the power viewer only displays power in the MW order. For this reason, it is necessary to create a power viewer that is able to display power in a wider range to complement the existing power viewer. The reactor power digital display device is built with OPC server, labview and utilizes the JKTO4 power channel which is used as a guide for determining the reactor power. From the test results, the reactor power digital display program succeeded in displaying the reactor power from the order of $\mathrm{kW}$ to $\mathrm{MW}$ and the calculation of the current conversion factor JKTO4 (amperes) to the power scale (watts) can be done accurately and automatically. All calculation results of the program can be saved into a file in Excel format as a database. This device can be applied in RSG-GAS in the hope that it can be used as a power display for low power to high power operations and as a means to support research on reactor power.
\end{abstract}

Keywords: Power viewer, Conversion Factor, Power channel, OPC server 


\section{PENDAHULUAN}

Daya yang dibangkitkan di RSGGAS tergantung dari tingkat kerapatan fluks neutron yang terjadi di dalam teras reaktor. Dalam mengoperasikan RSGGAS, penentuan besar daya berpedoman pada kanal pengukuran daya JKT04. Nilai daya reaktor hasil kalibrasi secara kalorimetri dikonversikan ke arus detektor JKT04 yang juga merupakan pengukur fluks neutron yang dibangkitkan pada teras reaktor mulai daya rendah hingga daya tinggi[1].

Saat ini penampil daya reaktor berdasarkan kanal pengukur daya tinggi JKT03 CX811/821/831/841 dan kanal pengukur radiasi JAC01 CR811/821/831. Penampil daya tersebut hanya menampilkan daya dalam orde MW, sedangkan reaktor RSG-GAS dioperasikan dari daya rendah $(\mathrm{kW})$ hingga daya tinggi (MW). Untuk itu perlu dibuat program penampil daya reaktor berdasarkan kanal daya JKT04 yang mampu menampilkan daya dalam range yang lebih lebar untuk melengkapi penampil daya yang ada.

Tampilan kanal daya JKT04 masih menggunakan meter analog dan dalam skala arus (ampere), untuk itu dibutuhkan faktor konversi. Faktor konversi adalah nilai watt untuk arus terkecil JKT04. Selama ini faktor konversi dihitung secara manual setelah reaktor dalam keadaan setimbang (setelah beroperasi $2 \times 24$ jam) ${ }^{[2]}$. Untuk mengetahui faktor konversi, terlebih dahulu dilakukan perhitungan daya kalorimetri reaktor berdasarkan perbedaan $\mathrm{T}$ inlet - outlet kolam reaktor, laju alir sistem pendingin primer reaktor dan laju alir sistem purifikasi reaktor. Perhitungan daya kalorimetri pada laju alir sistem pendingin primer sebesar $3144 \mathrm{~m}^{3} / \mathrm{jam}$ dan sistem purifikasi reaktor sebesar $33 \mathrm{~m}^{3} / \mathrm{jam}$ telah tersedia dalam bentuk tabel daya ${ }^{[3]}$.
Tabel tersebut digunakan operator untuk mengkalibrasi daya berdasarkan laju alir sistem pendingin primer dan sistem purifikasi yang sebenarnya. Setelah itu daya kalorimetri reaktor dibagi dengan arus JKT04 sehingga didapatkan nilai faktor konversi. Pada program penampil digital daya reaktor ini perhitungan faktor konversi dilakukan secara otomatis.

Pengujian dilakukan dengan membandingkan hasil perhitungan faktor konversi program dengan hasil perhitungan manual pada log Book kalibrasi daya. Dari hasil pengujian didapat nilai rata-rata error sebesar $0.25 \%$ untuk operasi regular $15 \mathrm{MW}$ dan $1.41 \%$ pada saat operasi daya penuh $30 \mathrm{MW}$. Selain itu program penampil daya digital berhasil menampilkan daya reaktor dari orde $\mathrm{kW}$ hingga MW dan menyimpan semua perhitungan ke dalam basis data format excel. Basis data ini dapat digunakan untuk penelitian yang berkaitan dengan daya kalorimetri reaktor dan selama ini belum ada fasilitas penyimpanan perhitungan daya kalorimetri dan faktor konversi secara real time. Tujuan pada penelitian ini adalah membuat penampil daya yang mampu menampilkan daya dari orde $\mathrm{kW}$ hingga MW yang dilengkapi dengan basis data untuk menyimpan hasil perhitungan daya kalorimetri dan faktor konversi.

\section{LANDASAN TEORI}

\section{Kanal Pengukuran Daya JKT04}

Detektor JKT04 merupakan pengukur fluks neutron yang dibangkitkan pada teras dari daya rendah hingga daya tinggi. Kanal pengukuran daya JKT04 menggunakan detektor neutron compenstated ion chamber $(\mathrm{CIC})$ yang berfungsi untu mengubah radiasi (neutron dan gamma) menjadi besaran listrik (arus) ${ }^{[4]}$. Sistem ini digunakan sebagai acuan untuk operasi reaktor daya rendah 
hingga daya tinggi, disamping itu kanal ini digunakan untuk pengendalian daya secara otomatis ${ }^{[5]}$.

\section{Penentuan Daya Reaktor}

Untuk menentukan daya reaktor, terlebih dahulu dilakukan perhitungan daya kalorimetri acuan. Daya kalorimetri merupakan perhitungan daya berdasarkan perbedaan T inlet (JE01 CT006) dan T oulet (JE01 CT001) teras reaktor dengan laju alir pendingin tetap [6]. Besarnya daya kalorimetri reaktor acuan dapat dihitung dengan Persamaan $1^{[7]}$.

Keterangan

$$
\begin{aligned}
& Q=W x \rho \times \mathrm{Cp} \times \Delta \mathrm{T} \\
& \Delta T=\text { Tin }- \text { Tout }- \text { fkoreksi } \\
& T b=\frac{T i n+T o u t}{2} \\
& \rho=1000 \times\left(1,0029-1,5838 \times 10^{-4} \times \mathrm{Tb}-2,847 \times 10^{-6} \times \mathrm{Tb}^{2}\right) \\
& \mathrm{C}_{\mathrm{p}}=4,167+0,05^{(-0,0734 \times \mathrm{Tb})}+0,0031 \times \mathrm{e}^{(0,0268 \times \mathrm{Tb})}
\end{aligned}
$$

$\mathrm{Cp}=$ panas spesifik pendingin reaktor (kW.det $/ \mathrm{kg}{ }^{\circ} \mathrm{C}$ )

$\mathrm{W}$ = laju alir sistem pendingin primer $\left(\mathrm{m}^{3} /\right.$ detik)

$\Delta \mathrm{T}=$ beda suhu outlet dan inlet $\left({ }^{\circ} \mathrm{C}\right)$

Tout $=$ Suhu outlet sistem pendingin primer reaktor $\left({ }^{\circ} \mathrm{C}\right)$

$\mathrm{F}$ koreksi $=$ beda suhu alami primersekunder

$\mathrm{Tb}=$ rerata suhu outlet dan inlet $\left({ }^{\circ} \mathrm{C}\right)$

Laju alir sistem pendingin primer dihitung dari laju alir pendingin primer (JE01 CF811/821/831) dan sistem purifikasi reaktor (KBE01 CF03). Pada perhitungan daya kalorimetri reaktor acuan laju alir pendingin primer ditetapkan sebesar $3144 \mathrm{~m}^{3} /$ jam dan laju alir sistem purifikasi sebesar $33 \mathrm{~m}^{3} /$ jam (untuk perhitungan terlebih dahulu dikonversikan ke $\mathrm{m}^{3} /$ detik) seperti pada tabel daya reaktor. Untuk panas spesifik dan kerapatan pendingin reaktor dapat dihitung dengan menggunakan Per-
Perhitungan daya kalorimetri acuan digunakan untuk menggantikan tabel daya yang digunakan untuk kalibrasi daya dan perhitungan faktor konversi secara manual. Untuk mengkalibrasi daya reaktor, laju alir sistem pendingin primer sebenarnya dibagi dengan laju alir sistem pendingin primer daya kalorimetri acuan dikali daya kalorimetri acuan seperti Persamaan 6 ${ }^{[7]}$.

$$
Q 1=\frac{(E+F)}{(3144+33)} \times Q
$$

Keterangan

$\mathrm{Q}=$ daya kalorimetri reaktor acuan $(\mathrm{kW})$

Q1= daya kalorimetri reaktor sebenarnya

$\mathrm{E}=$ laju alir pendingin primer sebenarnya ( $\left.\mathrm{m}^{3} / \mathrm{jam}\right)$

$\mathrm{F}=$ laju alir sistem purifikasi reaktor sebenarnya ( $\left.\mathrm{m}^{3} / \mathrm{jam}\right)$

Untuk menghitung faktor konversi JKT04 menggunakan Persamaan $7^{[8]}$.

$F K=\frac{Q 1 \text { Watt }}{I_{\text {JKT } 04}} \times 10^{-10}$

Keterangan :

$\mathrm{IJKT04}_{\mathrm{JK}}$ Besarnya arus JKT04 pada operasi daya reaktor Q1 MW 
Faktor konversi adalah nilai watt untuk arus terkecil kanal daya JKT04 (1.10-10 Ampere). Pada program penampil digital daya reaktor nilai faktor konversi digunakan untuk perhitungan daya dengan menggunakan Persamaan $8^{[8]}$.

$Q 2=F K . I_{\text {JKTO4 }}$

Keterangan :
Q2 = Daya kalorimetri reaktor berdasarkan arus kanal daya JKT04
$\mathrm{FK}=$ Faktor Konversi

\section{National Instruments OPC Server}

National Instruments (NI) OPC Server adalah salah satu antar muka LabVIEW agar dapat berkomunikasi dengan berbagai perangkat luar seperti halnya $\mathrm{PLC}^{[9]}$. Sistem instrumentasi yang kompleks membutuhkan sebuah standar komunikasi yang dapat mengakomodasi perbedaan komunikasi pada setiap perangkat. OPC (OLE for Process Control) adalah mekanisme standar untuk berkomunikasi ke berbagai sumber data, baik perangkat di lingkungan pabrik, atau basis data di ruang kendali [10].

\section{METODOLOGI}

Program penampil daya reaktor dirancang memiliki beberapa fitur antara lain mampu melakukan perhitungan faktor konversi secara otomatis, menampilkan daya reaktor dengan range yang lebih lebar (orde $\mathrm{kW}$ sampai dengan MW) dan menyimpan semua hasil perhitungan dalam basis data dengan format excel.

\section{Pembuatan program penampil digital daya reaktor}

Langkah pertama adalah penentuan input. Input yang digunakan adalah yang berkaitan dengan perhitungan faktor konversi daya reaktor seperti pada Tabel 1.

Tabel 1. Inputan sub program perhitungan daya kalorimetri

\begin{tabular}{ll}
\hline \multicolumn{1}{c}{ Parameter input } & Skala pengukuran maksimal \\
\hline JE01 CT001 & $60^{\circ} \mathrm{C}$ \\
JE01 CT006 & $60^{\circ} \mathrm{C}$ \\
JE01 CF811 s/d CF831 & $3400 \mathrm{~m}^{3} / \mathrm{jam}$ \\
KBE01 CF003 & $60 \mathrm{~m}^{3} / \mathrm{jam}$ \\
Arus JKT04 & $5.10^{-4} \mathrm{~A}$ \\
Multirange JKT04 & \\
\hline
\end{tabular}

Sinyal-sinyal input diambil dari output PLC yang berupa sinyal analog (arus) dan digital. Untuk T inlet, Toutlet, laju sistem pendingin primer, laju sistem purifikasi dan arus kanal daya JKT04 berupa sinyal analog sedangkan inputan multirange berupa sinyal digital. Inputan yang berupa sinyal analog dirubah menjadi data numerik oleh software OPC sever dan inputan digital tetap berupa data digital. Selanjutnya output OPC sever diolah menggunakan program labview untuk perhitungan daya kalorimetri acuan, daya kalorimetri reaktor dan faktor konversi berdasarkan Persamaan 1 sampai dengan 8. Untuk diagram alir sinyal input seperti pada Gambar 1. 


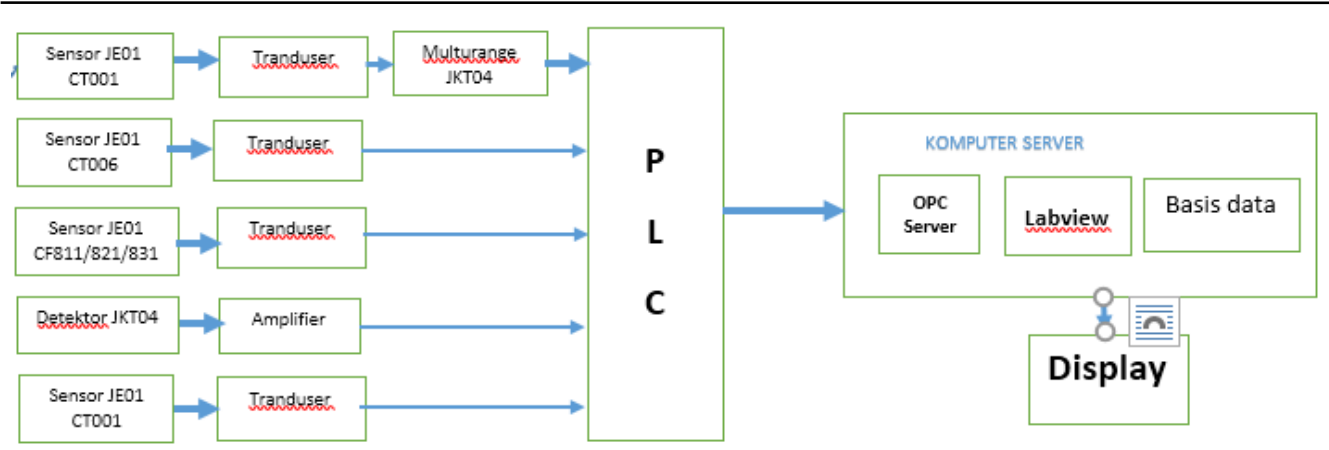

Gambar 1 . Blok diagram alir sinyal input

\section{Pengujian program penampil digital HASIL DAN PENGUJIAN \\ daya reaktor}

Pengujian program dilakukan dalam 4 tahap:

1. Pengujian koneksi PLC-NI OPC server.

2. Perbandingan hasil perhitungan faktor konversi program dengan perhitungan manual pada log-book kalibrasi daya.

3. Pengujian kemampuan program dalam menampilkan daya dari orde kW hingga MW.

4. Pengujiankemampuan program dalam menyimpan data input dan hasil perhitungan ke dalam basis data.
Program penampil digital daya reaktor telah selesai dibuat dan diuji pada tanggal 6,14,26,27 Mei 2018 untuk operasi regular $15 \mathrm{MW}$ dan tanggal 15 Mei 2018 untuk operasi daya penuh 30 MW dengan hasil sebagai berikut :

\section{Konfigurasi Hardware}

Konfigurasi hardware yang digunakan untuk pembuatan program penampil digital daya reaktor seperti pada Gambar 2.

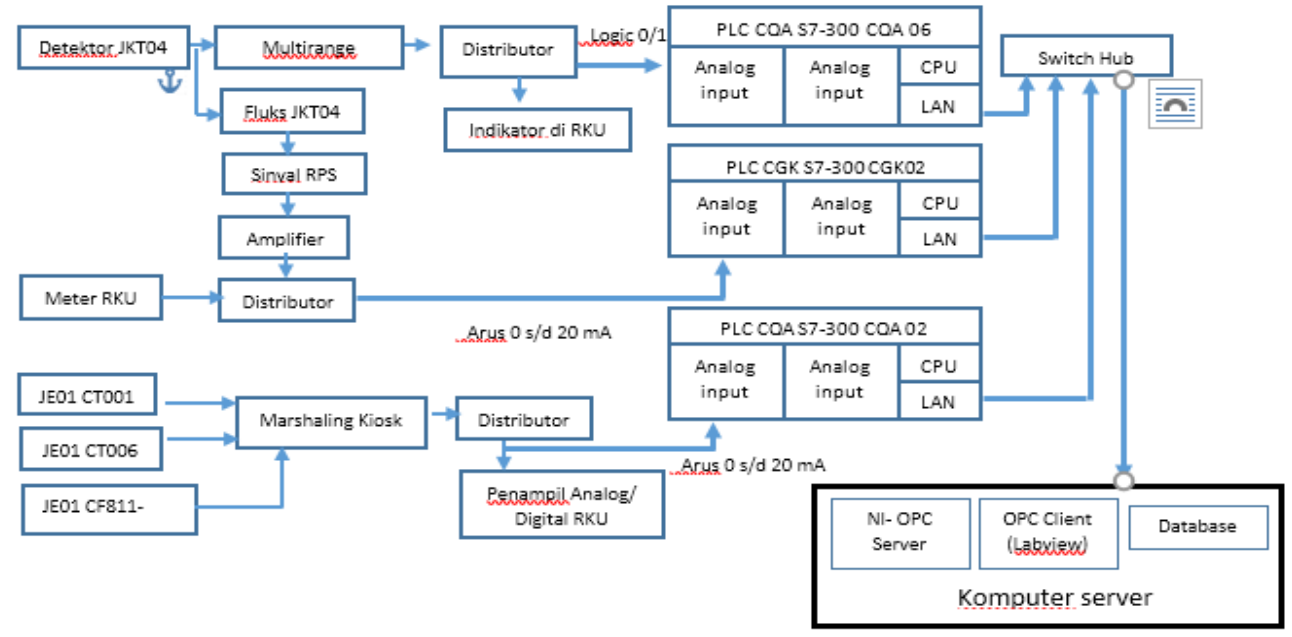

Gambar 2. Blok diagram konfigurasi hardware system 
Sinyal-sinyal dari inputan tersebut terdiri dari sinyal analog dan digital. Untuk inputan T inlet, Toutlet, laju sistem pendingin primer, laju sistem purifikasi dan arus kanal daya JKT04 berupa sinyal analog sedangkan untuk inputan multirange berupa sinyal digital. Sinyal digital multirangemasuk ke dalam PLC dan sinyal digital keluaran dari PLC dikirim ke meja kendali RKU (ruang kendali utama) RSG. Sedangkan sinyal analog dari inputan tersebut akan masuk ke pengondisi sinyal kemudian dilewatkan distributor aktif yang berfungsi mendistribusikan sinyal keluaran dari pengondisi sinyal menjadi dua sinyal yang sama besar dengan nilai masukan- nya, satu untuk masukan PLC dan satu untuk ditampilkan di panel tegak ruang kendali utama RSG GAS. Sinyal-sinyal yang digunakan untuk progam penampil digital daya diambil dari port komunikasi PLC yang dihubungkan dengan komputer menggunakan kabel LAN dan perangkat lunak NI-OPC server dengan protokol TCP/IP.

\section{Hasil pemrograman}

Dari hasil pemrograman, program penampil digital daya reaktor memiliki 2 sisi front panel seperti ditunjukan pada Gambar 3a dan 3b.

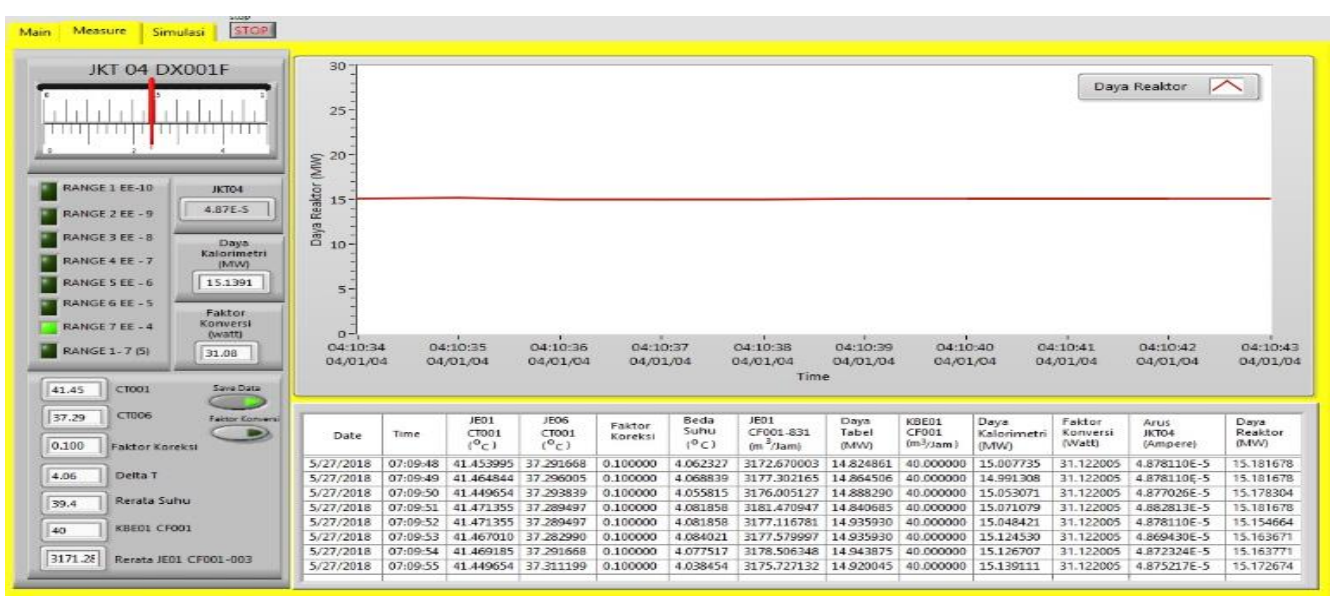

Gambar 3.a Front panel input dan hasil perhitungan program

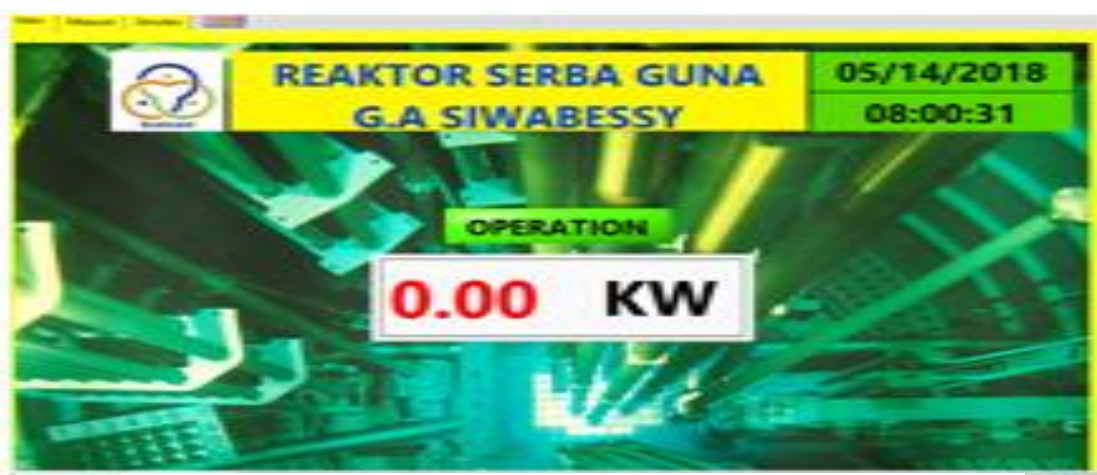

Gambar 3.b Front pane/ tampilan daya reaktor 
Untuk blok diagram program seperti pada Lampiran 1.

Hasil pengujian koneksi PLC-NI OPC server
Sebelum program penampil digital daya reaktor diuji terlebih dahalu dilakukan pengujian koneksi PLC- NI OPC server dengan hasil seperti pada Gambar 4 .

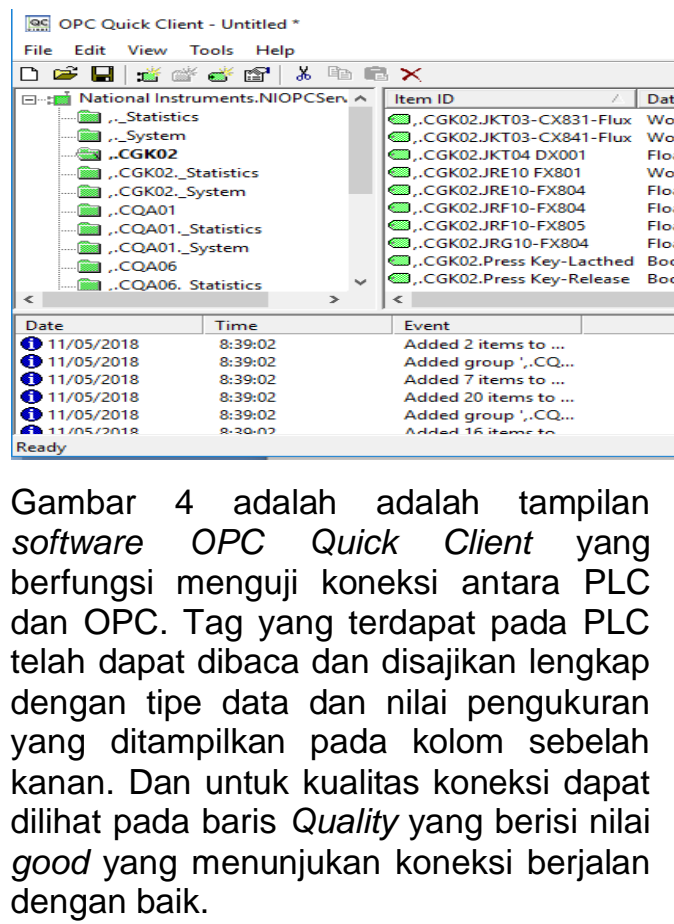

Hasil pengujian perhitungan faktor konversi program penampil daya digital

Hasil perhitungan faktor konversi oleh program dihitung berdasarkan persamaan daya kalorimetri dengan contoh perhitungan sebagai berikut :

Diketahui data diambil dari operasi reaktor tanggal 27/05/2019:

Tinlet $=41.47{ }^{\circ} \mathrm{C}$, Toutlet $=37.31{ }^{\circ} \mathrm{C}, \mathrm{E}=$ $3188.37 \mathrm{~m}^{3} / \mathrm{jam}, F=40 \mathrm{~m}^{3} / \mathrm{jam}, \mathrm{I}_{\mathrm{JKT} 04}=$ $4.83 \mathrm{E}-5 \mathrm{~A}, \Delta T=4,06^{\circ} \mathrm{C}, \mathrm{Tb}=39,39^{\circ} \mathrm{C}$

Ditanyakan Faktor Konversi (FK) ? Jawab :

- Menghitung kerapatan dan panas spesifik pendingin primer berdasarkan Persamaan 4 dan 5

$$
\begin{aligned}
\rho= & 1000 \times\left(1,0029-1,5838 \times 10^{-4} \times \mathrm{Tb}\right. \\
& \left.-2,847 \times 10^{-6} \times \mathrm{Tb}^{2}\right) \\
= & 1000 \times\left(1,0029-1,5838 \times 10^{-4} \mathrm{x}\right. \\
& \left.39.39-2,847 \times 10^{-4} \times 39.39^{2}\right) \\
= & 992.24 \mathrm{~kg} / \mathrm{m}^{3} \\
\mathrm{C}_{p}= & 4,167+0,05^{(-0,0734 \times \mathrm{Tb})}+0,0031 \mathrm{x} \\
& \mathrm{e}^{(0,0268 \times \mathrm{Tb})} \\
= & 4,167+0,05^{(-0,0734 \times 39.39)}+0,0031 \mathrm{x} \\
& \mathrm{e}^{(0,0268 \times 39.39)} \\
= & 4.18 \mathrm{~kW} . \operatorname{det} / \mathrm{kg}^{\circ} \mathrm{C}
\end{aligned}
$$

- Menghitung daya kalorimetri acuan berdasarkan Persamaan

$$
\begin{aligned}
& Q=W x \rho \times \mathrm{Cp} \times \Delta \mathrm{T} \\
& =3177 / 3600 \times 992.24 \times 4.18 \times 4.06 \\
& =14860 \mathrm{~kW}
\end{aligned}
$$

- Menghitung daya kalorimetri reaktor berdasarkan Persamaan 6

$$
Q 1=\frac{(E+F) \cdot Q}{(3144+33)}
$$

$$
\begin{aligned}
Q 1 & =\frac{(3188.37+40) \cdot 14860}{(3144+33)} \\
& =15100 \mathrm{~kW}
\end{aligned}
$$

- Menghitung Faktor Konversi berdasarkan Persamaan 7

$$
\begin{array}{r}
F K=\frac{15,1 \times 10^{6}}{0.483 \times 10^{-4}} \times 10^{-10} \\
=31.26
\end{array}
$$

Dengan cara yang sama didapatkan hasil seperti pada Tabel 2. 
Tabel 2. Hasil pengujian perhitungan faktor konversi operasi regular $15 \mathrm{MW}$

\begin{tabular}{|c|c|c|c|c|c|c|}
\hline No & Tanggal & waktu & $\begin{array}{c}\text { Faktor konversi } \\
\text { (Watt) } \\
\text { Log Book kalibrasi } \\
\text { daya RKU }\end{array}$ & $\begin{array}{c}\text { Faktor konversi } \\
\text { (Watt) } \\
\text { Penampil } \\
\text { program }\end{array}$ & Selisish & $\begin{array}{c}\text { Error } \\
(\%)\end{array}$ \\
\hline 1 & $06-05-18$ & 9:01:02 & 30.50 & 30.435865 & 0.07 & 0.22 \\
\hline 2 & $14-05-18$ & $0: 33: 42$ & 29.72 & 29.677313 & 0.04 & 0.14 \\
\hline 3 & $26-05-18$ & $10: 30: 12$ & 30.48 & 30.293614 & 0.19 & 0.61 \\
\hline 4 & $27-05-18$ & $6: 55: 18$ & 31.26 & 31.260254 & 0.00 & 0.01 \\
\hline \multicolumn{6}{|c|}{ Rata-rata error } & 0.25 \\
\hline
\end{tabular}

Tabel 3. Hasil pengujian perhitungan faktor konversi operasi $30 \mathrm{MW}$

\begin{tabular}{ccccccc}
\hline No & Tanggal & waktu & $\begin{array}{c}\text { Faktor konversi } \\
\text { (Watt) } \\
\text { Log Book kalibrasi } \\
\text { daya RKU }\end{array}$ & $\begin{array}{c}\text { Faktor konversi } \\
\text { (Watt) } \\
\text { Penampil } \\
\text { program }\end{array}$ & Selisish & $\begin{array}{c}\text { Error } \\
\text { (\%) }\end{array}$ \\
\hline 1 & $15-05-18$ & 12.40 .05 & 31.29 & 30.70 & 0.59 & 1.89 \\
\hline 2 & $15-05-18$ & 13.19 .05 & 30.58 & 30.34 & 0.24 & 0.78 \\
\hline 3 & $15-05-18$ & 13.45 .05 & 29.88 & 29.41 & 0.47 & 1.56 \\
\hline \multicolumn{7}{c}{ Rata-rata error } \\
\hline
\end{tabular}

Dari hasil pengujian didapat nilai ratarata error sebesar $0.25 \%$ untuk operasi regular dan $1.41 \%$ pada saat operasi daya penuh $30 \mathrm{MW}$. Hal ini menunjukan program penampil digital daya reaktor memiliki tingkat ketelitian yang tinggi ${ }^{[1]}$.
Hasil pengujian program menampilkan daya reaktor dari orde $\mathrm{kW}$ sampai dengan MW

Selain itu program penampil daya digital diuji untuk menampilkan daya rendah hingga daya tinggi seperti pada Gambar 5.

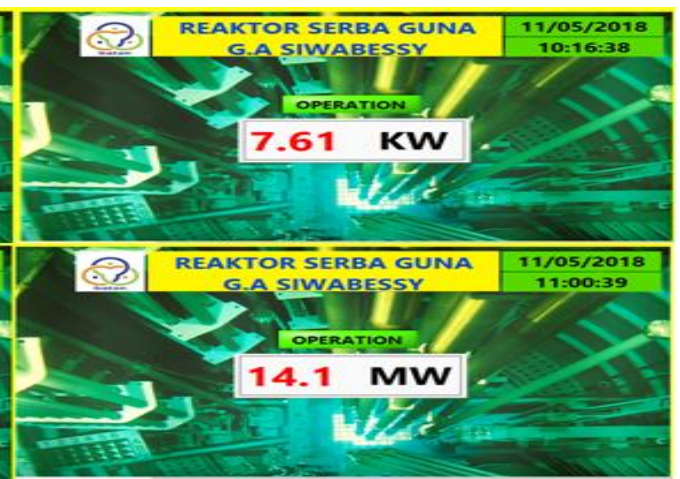

Gambar 5. Hasil pengujian penampil daya untuk menampilkan daya rendah hingga tinggi 
Hasil pengujian fasilitas penyimpanan data program penampil digital daya reaktor

Semua parameter input yang berkaitan dengan perhitungan faktor konversi, hasil perhitungan daya kalorimetri acuan, perhitungan daya kalorimetri reaktor sebenarnya, faktor konversi dan daya reaktor dapat disimpan di dalam basis data seperti pada Lampiran 2.

\section{KESIMPULAN}

Penelitian ini berhasil membuat penampil digital daya RSG-GAS yang mampu menampilkan daya dari orde $\mathrm{kW}$ sampai dengan MW berdasarkan kanal daya JKT04 menggunakan software PLC, OPC Server dan labview yang dilengkapi basis data format excell yang sangat bermanfaat bagi operator untuk mengamati perubahan daya terutama pada operasi daya rendah dan memudahkan operator untuk mengetahui faktor konversi secara real time.

\section{DAFTAR LAMPIRAN}

Lampiran 1. Blok diagram program penampil daya digital

Lampiran 2. Cuplikan data base operasi tanggal 15/05/2018 (pukul 12.40.05)

\section{DAFTAR PUSTAKA}

[1] Wiranto.S,2011, Pengaruh Garpu Penyerap Uji Terhadap Reaktivitas Teras dan Kalibrasi Raya RSGGAS, Prosiding Seminar Penelitian Dan Pengelolaan Perangkat Nuklir Pusat Teknologi Akselerator dan Proses Bahan.

[2] PRSG-BATAN, 2016, Standar Operasional Prosedur Kalibrasi Daya Reaktor RSG-GAS Nomor: SOP 007.003/RN 00 01/RSG 2.2, Serpong: PRSG - BATAN.

[3] Sigit. S, 2019, Evaluasi Kemampuan Sistem Pendingin Primer Reaktor
Setelah Revitalisasi Menara Pendingin, Buletin Pengelolaan Reaktor Nuklir Volume XVI Nomor 1, Serpong: PRSG-BATAN.

[4] Laporan Analisis Keselamatan, RSG-GAS Rev 10.1 Desember 2011.

[5] Sukiyanto dkk,2018, Analisis Pengoperasian Reaktor RSG-GAS Pada Teras 96 Dengan Daya Maksimum 30 MW, Buletin Pengelolaan Reaktor Nuklir 2018, Nuklir,Yogyakarta.

[6] Sukiyanto, Nurtanto.B, Pengukuran Faktor Koreksi Kalibrasi Daya 15 MW Dan 30 MW Di Reaktor RSGGAS, Buletin Pengelolaan Reaktor Nuklir Vol 14 April 2017.

[7] Isnaeni.D,1995, Tabel Konversi Daya, BATAN, Serpong.

[8] Slamet Wiranto, Diktat Praktikum Kalibrasi Daya RSG-GAS, Diklat Operator Reaktor, P2TRR-BATAN, September 2003

[9] Rachman, AgusNur, 2015, Pengembangan Sistem Online Monitoring Parameter Proses RsgGas Berbasis OPC, Teknofisika Nuklir, Sekolah Tinggi Teknologi Nuklir, Yogyakarta

[10] Supriyatman.B, 2016

Pengembangan Sistem Pemantau Penggerak Batang Kendali Reaktor Serba Guna G.A Siwabessy Berbasis Labview, Teknofisika Nuklir, Sekolah Tinggi Teknologi Nuklir, Yogyakarta.

[11] Kumalasari.A, 2017, Pengembangan Metode Rapid Test Dalam Penentuan Ash Content Dan Calorific Value Batubara Di Laboratorium PT Jasa Mutu Mineral Indonesia, Jurnal Atomik, 2017, 02 (1) hal 121-127. 


\section{Lampiran 1. Blok diagram program}
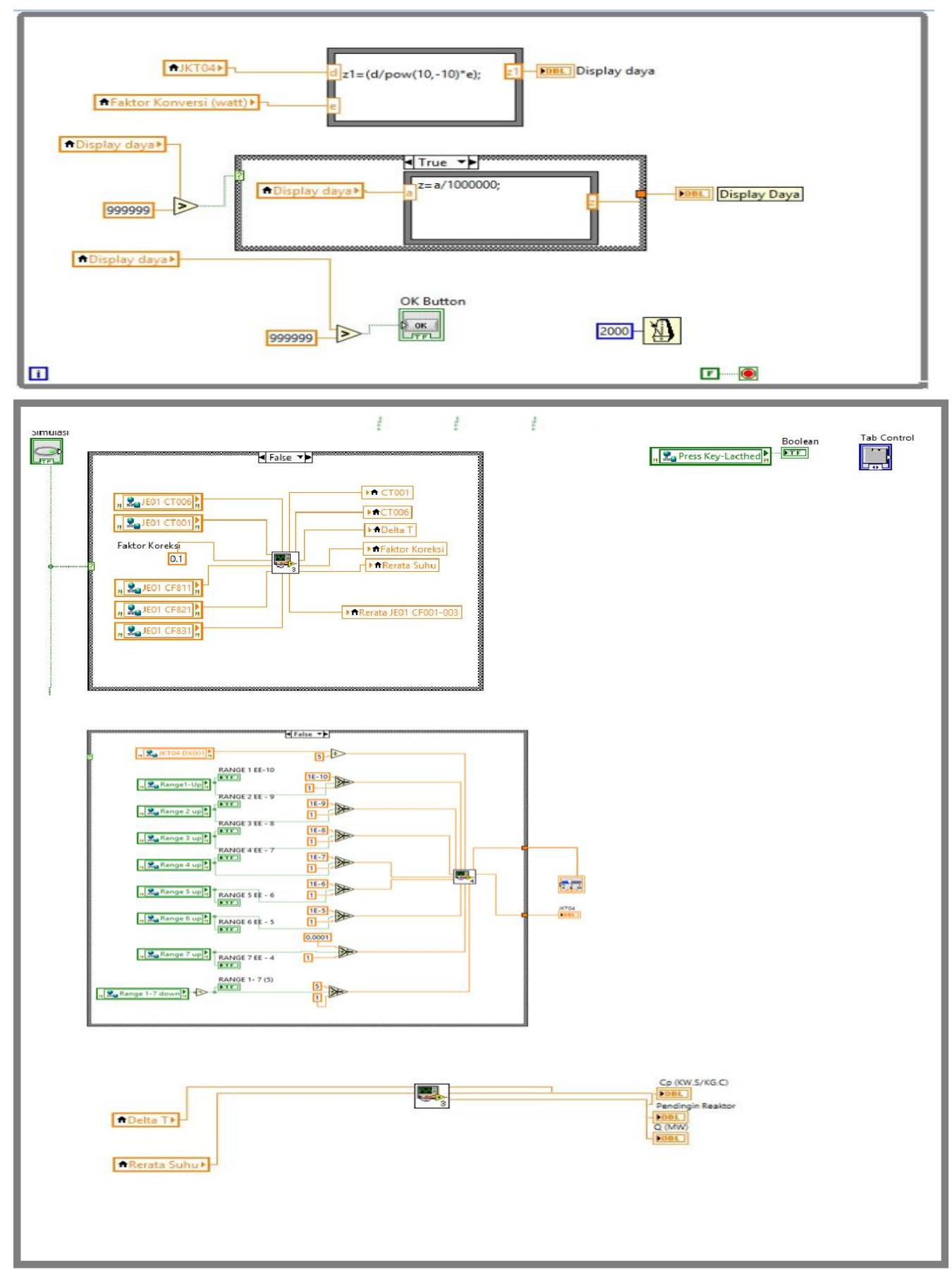

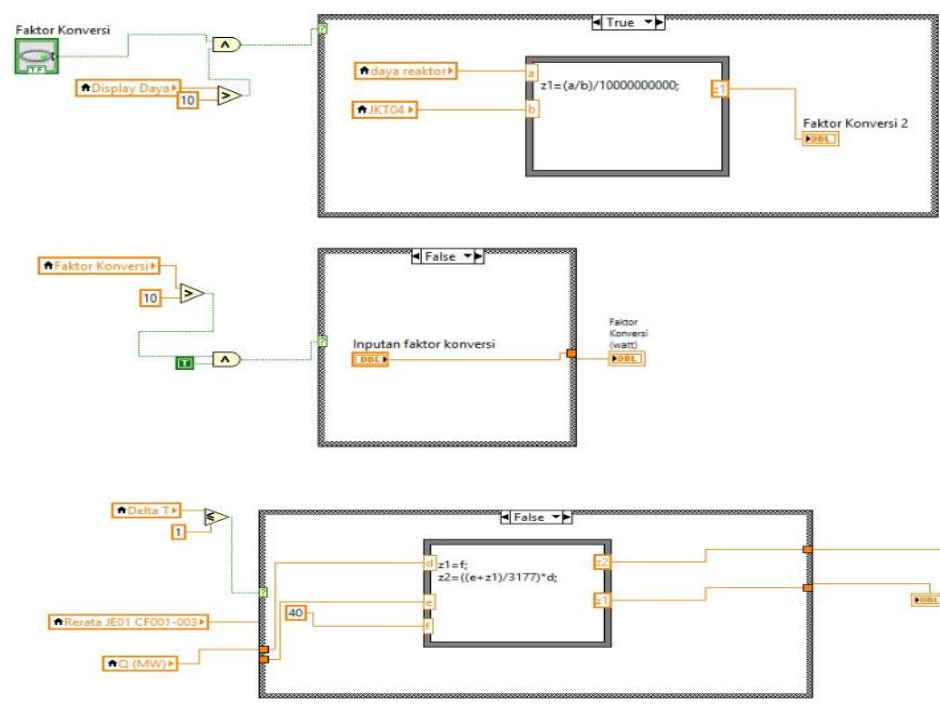

in daya realtorn

[09999] $\gg$

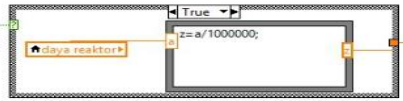

Dint Raya Dalorimetri Imm

(7000-

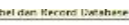

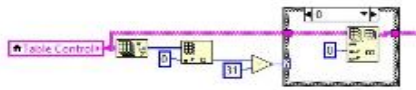
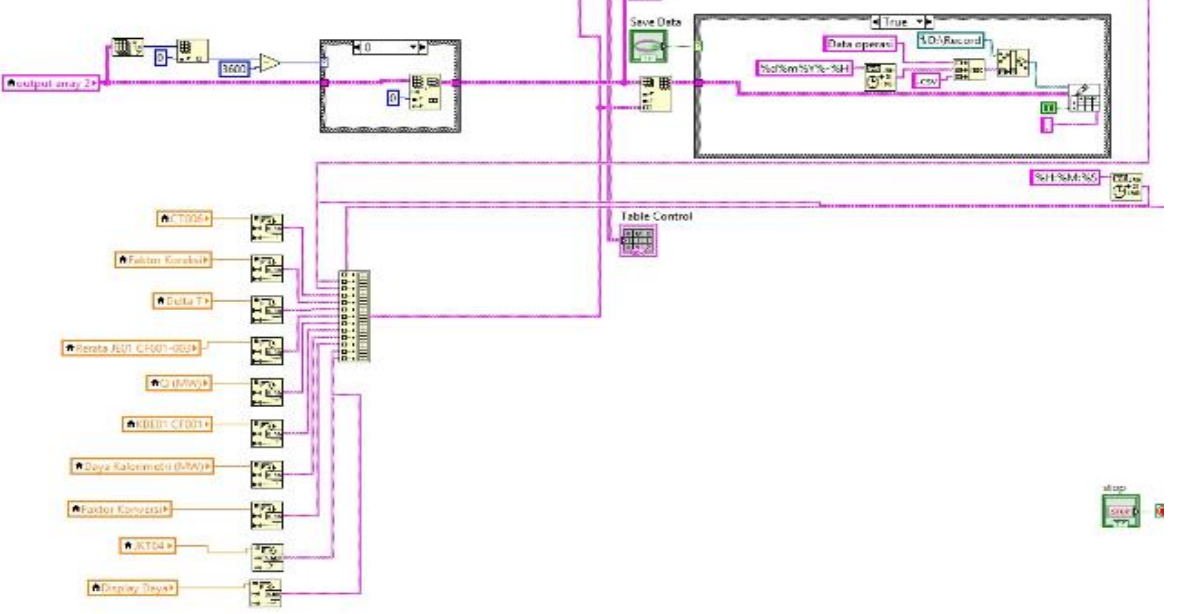
Lampiran 2. Cuplikan data base operasi tanggal15/05/2018 (pukul 12.40.05)

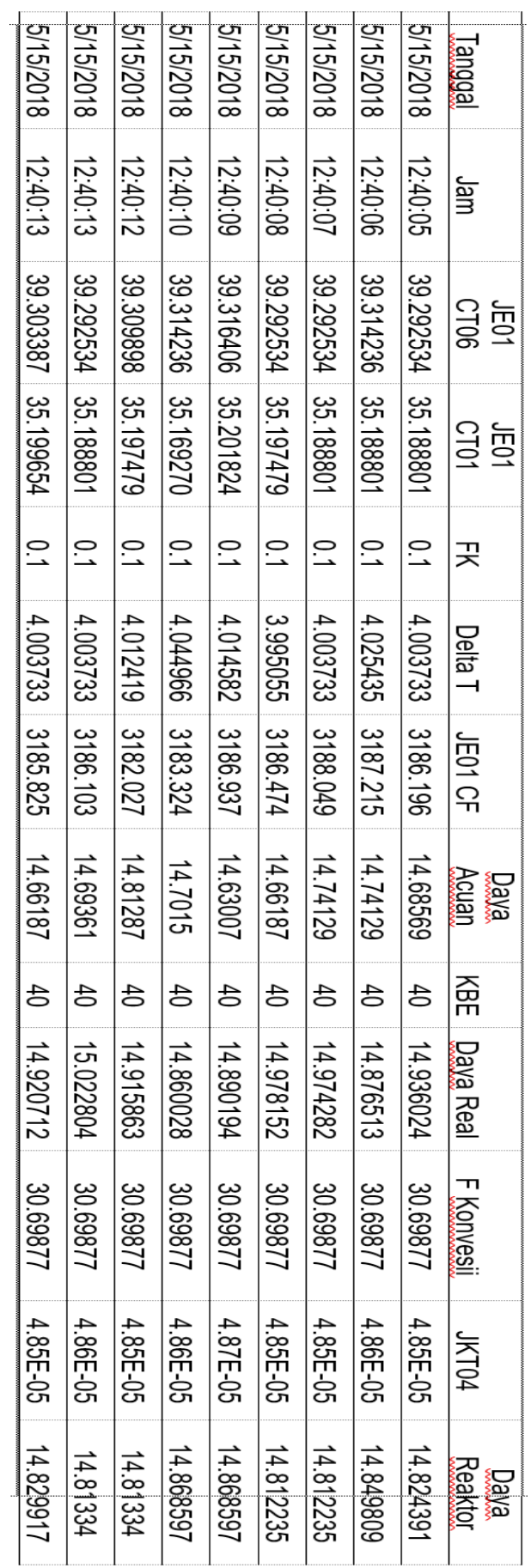

